\title{
La aplicación por los Ayuntamientos del impuesto de Usos y Consumos cedido por el Estado
}

En la aplicación del nuevo sistema de Hacienda Municipal ciestaca por su importancia la del Impuesto de Usos y Consumıos de Lujo, cedido a los Ayuntamientos.

Un año de experiencia sugiere motivos suficientes a considerar y vamos a tratar aqui de algunos observados con ocasión de la organización y administración del Impuesto en el Ayuntamiento de Bilbao, y que conjugados con los vistos en otras Corporaciones pueden constituir un conjunto de material informativo interesante.

Para destacar la importancia que tiene este impuesto en la economía de los Municipios de cierto rango y con.características de las ciudades modernas, daremos las siguientes cifras comparativas referidas a Bilbao y al ejercicio de 1946 :

\section{Recaudación directa por administración}

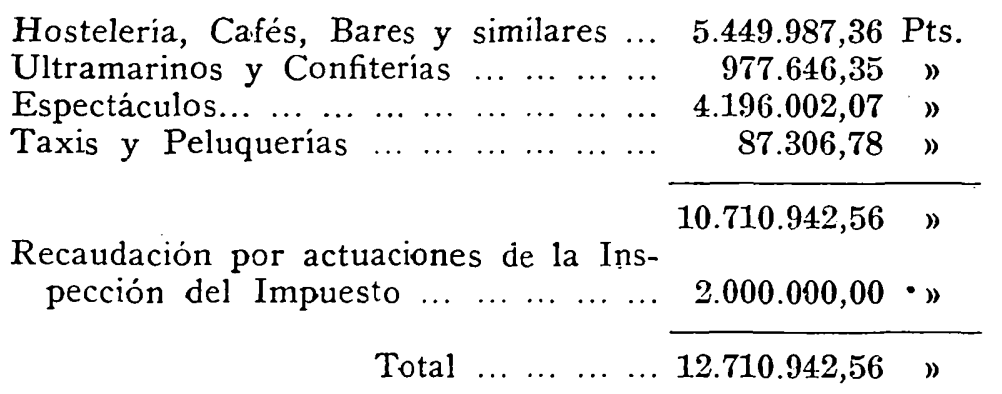


Esta cantidad total puede aún mejorar, puesto que la cifra de 2.000.000 de pesetas consignada para los resultados de la acción inspectora está calculada tomando como base la comprobación ya realizada del ramo de Hostelería y Similares, estando aún en curso en este momento la de otros conceptos.

Valores liquidados en el ejercicio de 1945 por las Participaciones y Arbitrios suprimidos

Participación en la Contribución Territorial Urbana... $\ldots \ldots \ldots \ldots \ldots \ldots$

Idem en la Patente Nacional de Vehículos de motor... ...................

Idem en la Contribución Industrial ... Idem en el Impuesto sobre Ventas de

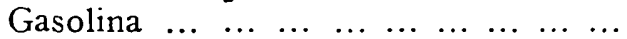
Idem en el de Cédulas Personales... ... Arbitrio sobre el producto neto de las Compañias... $\ldots \ldots \ldots \ldots \ldots \ldots$

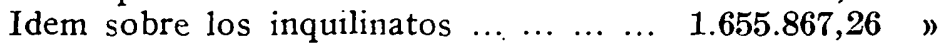

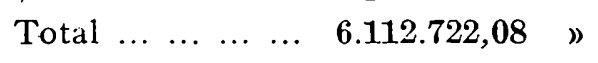

Como se aprecia comparando las cifras totales que quedan apuntadas, el rendimiento del Impuesto cedido cubre por sí solo con un margen de exceso de $\mathbf{6 . 5 9 8 . 2 2 0 , 4 8}$ pesetas la baja que para el Ayuntamiento de Bilbao representan las supresiones citadas.

Esta importancia del Impuesto y sus particulares características que se traducen en dificultades prácticas muy acusadas para llegar a conocer con la máxima aproximación sus verdaderas bases imponibles, obliga a.los Ayuntamientos a cuidar mucho la organización de su administración y a tener acierto al escoger e! procedimiento a emplear.

En principio parece aconsejable seguir el procedimiento de las declaraciones juradas, con comprobación e inspección de las mismas para contar con una experiencia propia y lograr así un conocimiento directo de las actividades de los contribuyentes, de sus hábitos fiscales, de sus posibilidades, de las bases 
imponibles por ventas, consumiciones, servicios, espectáculos, etcétera, conocimiento que es imprescindible a mi juicio, para pasar con alguna garantía a las experiencias o del sistema de concierto o del de cobro a la entrada de las poblaciones.

Este sistema de declaraciones juradas ha sido por las razones expuestas el que ha empleado el Ayuntamiento de Bilbao con los resultados que quedan apuntados.

Las principales observaciones y enseñanzas recogidas son las siguientes:

A) Que en los espectáculos con entrada es más difícil la desviación y defraudación del impuesto y que el sistema más conveniente y práctico para evitarla es el de celebrar conciertosliquidación que consisten en líneas generales en lo siguiente:

Como requisito previo el sellado y cuenta de cargo y descargo del billetaje a las Empresas.

La fijación de unas cifras anuales a las respectivas Empresas de espectáculos que las abonarán por dozavas partes.

$Y$ en fin de ejercicio y con vista y base de los libros documentos y de las cuentas de cargo y descargo de billetaje la práctica de una liquidación definitiva.

A las Empresas que han ingresado con èxceso en relación con su cifra de concierto se les hacen las devoluciones correspondientes.

A las que han ingresado menos se les cobran las diferencias.

Este sistema lo ha empleado el Ayuntamiento de Bilbao con éxito. El sellado previo y las cuentas de cargo y descargo de billetaje los practica y lleva como operaciones iniciales y básicaś la Oficina Provincial de Administración del Impuesto para la Protección de Menores, con la que la Administración municıpal tiene establecido un servicio coordinado de control e intormación.

B) Que en los conceptos de consumiciones, ventas y servicios (hoteles, bares, cafés, tabernas y similares, ultramarinos, confiterías, taxis y peluquerías) las declaraciones vienen en general con cifras bastante inferiores a las reales, lo que repercute en merma de la recaudación ordinaria.

C) Que hay una desviación bastante importante del impues- 
to que sin embargo de percibirse por los industriales y comerciantes de los compradores, consumidores y ujuarios, no es entregado total $\mathrm{y}$ fielmente a la Administración municipal. En una paiabra, existe un hábito de margen de aprovechamiento especulativo del impuesto, contra el que es difícil luchar.

D) La desgravación del Impuesto para los vinos y sidras corrientes que se vendan para su consumo fuera.de los establecimientos, es una importante fisura en el sistema por la cual se evaden del mismo sin posible eficaz control, miles y miles de litros que en realidad son consumidos en los bares, tabernas y establecimentos similares.

E) Que la diferencia de tipo de gravamen para los vinos de marca, cervezas y sidras embotelladas y licores, según que se consuman en establecimientos de hostelería, bares, cafés, taternas y similares, o se vendan para consumirlos fuera de los establecimientos, perturba asimismo la buena fiscalización, introduciendo un elemento de clasificación diferenciada que permite operar con provecho a los industriales y además, en cierto modo, deja mal parada la justicia distributiva, porque en una gran proporción el consumo de vinos embotellados de marca $y$ licores fuera de los establecimientos es un consumo de lujo de tanta categoría como el realizado en aquéllos, pues hay muchos particulares acomodados que siguiendo modas al uso montán bares domésticos y disfrutan de la desgravación que representa la diferencia del tipo del 20 por 100 al tipo del 10 por 100 .

También, y ello es muy importante, esta diferenciación dificulta casi totalmente una normal y buena aplicación del procedimiento de cobro a la entrada a las poblaciones, pues siendo dos los tipos se comprende fácilmente: a) que si se ponen por equivalencia tipos de gravamen de entrada distintos según el 'destino de los vinos y licores, se crea un incentivo poderoso para el falseamiento de las declaraciones, que ocasionaría perjuicios y trastornos notables y una complicación en la administración; b) que si para evitar estos inconvenientes se pone un tipo de equivalencia único, éste habrá de regularse por el más reducido, con la consiguiente minoración de rendimientos.

F) Que la actual regulación de la aplicación del impuesto 
a los almuerzos y comidas, limitándolo a las que se sirvan en hoteles y restaurantes de las clases primera y de lujo no solamente no es justa, porque en establecimientos de inferiores categorías (ya por clasicismo de platos o de cocinas especiales, o por otros motivos de ocasión y lugar) se sirven comidas tan caras y de más lujo, en muchas ocasiones, que en aquéllos, sino forque además en la práctica basta un simple cambio de clasificación realizado con las fórmulas oficiales de rigor para evadirse del Impuesto.

En el procedimiento de declaraciones juradas hemos de confesar que la lucha contra las ocultaciones y desviaciones del Impuesto, que apunto en los apartados $B$ ) y $C$ ), no es asunto fácil, porque los contribuyentes preparan bien sus defensas, unas veces llevando y exhibiendo cuentas y documentos bien crdenados, pero cuya veracidad es dudosa, y otras por el contrario, con un estudiado y premeditado confusionismo y una ausencia total o parcial de datos, comprobantes y cuentas.

Hay que organizar por consiguiente un Servicio Especial de Inspección del Impuesto bien dotado de personal en número y en calidad, pues para que la labor resulte eficaz y aleccionadora ha de realizarse a fondo y con el tiempo que se requiera sobre' cada industrial o comerciante, dándose sensación de seriedad y de competencia.

E1 Ayuntamiento de Bilbao, inspirándose en este criterio, ha organizado su Servicio a base de funcionarios de sus plantillas administrativas con títulos de Profesores o Peritos mercantiles. a los que ha dado credenciales provisionales de Inspectores y quienes en servicio de tarde y sin más remuneración.que una participación en las cuotas que se ingresen como consecuencia de sus actuaciones personales y directas, vienen trabajando con resultados muy satisfactorios.

La actuación de la Inspección está complementada y auxiliada con un control y registro a cargo del Cuerpo de Arbitrios Municipales de las ventas a clientes minoritarios en plaza, que realizan los vendedores al por mayor de vinos, licores y cervezas y las fábricas de estos últimos artículos que están instaladas en el término. 
Una Junta Municipal de Valoraciones fiscales completa el cuadro de la organización.

Para cerrar la fisura de evasión del Impuesto al amparo de la desgravación total de los vinos y sidras corrientes que se vendan para el consumo fuera de los establecimientos a que me refiero en el apartado $D$ ), el remedio es sencillo, bastaría añadir un nuevo párrafo al epígrafe $\mathbf{1 8}$ de las Tarifas que diría así:

"El despacho o venta en esta clase de establecimientos de vinos y sidras corrientes para su consumo fuera de los mismos, se estimará como consumición a los efectos de la aplicación del impuesto de este epígrafe."

La solución sería radical y justa, porque es notorio y considerable el fraude a que viene dando ocasión el uso que se hace en la práctica de esta desgravación.

Las dificultades y trastornos recogidos en el apartado E) provenientes de la diferencia de tipos de gravamen para los vinos de marca, cervezas y sidras embotelladas y licores, pueden obviarse fácilmente dando la siguiente nueva redacción al epígrafe 20 del Impuesto:

Epigrafe 20.-Ventas en cualquier establecimiento para su consumo fuera de ellos:

De vino embotellado con marca, cerveza, sidra embotellada y licores $\ldots \ldots \ldots \ldots \ldots \ldots \ldots$

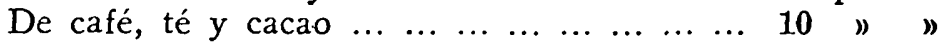

Esta solución tiene una coincidencia con el criterio que ya existe en la tarifación respecto a los artículos de confiteria, fara los cuales rige el mismo tipo del 20 por 100 de gravamen, se consuman dentro o fuera de los establecimientos que los expenden, criterio que parece debe mantenerse por equivalencia cuando se trata de artículos tan de consumo de lujo como lo son los vinos y licores de marca.

El defecto señalado en el ápartado $F$ ) respecto de la limitación de aplicación del Impuesto a sólo los almuerzos y comidas que se sirvan en hoteles y restaurantes de las clases primera y de lujo puede y debe corregirse siguiendo el criterio seguido 
por la Hacienda Pública con ocasión del establecimiento del recargo para primar artículos de primera necesidad.

En efecto, al administrar el Ayuntamiento este recargo hemos estado viendo cómo mientras en toda clase de establecimientos se aplicaba el mismo por las minutas especiales y aún por las corrientes servidas, en cambio el Impuesto, reducido a su mínima expresión, se limitaba a los cada vez más escasos establecimientos clasificados en las categorías de primera y de lujo.

No sugiero que la extensión del impuesto sea tan amplia como la del recargo, es decir, que deba alcanzar a las minutas ccrrientes, pero sí que se aplique a las cartas o minutas especiales se sirvan donde se sirvan.

Para ello convendría y bastaría dar la siguiente nueva reciácción al epígrafe 19 :

\section{Epigrafe 19:}

Consumiciones en Hoteles, Restaurantes y establecimientos similares, en servicios a la carta o minutas especiales, siempre que tratándose de Hoteles no formen parte de. la

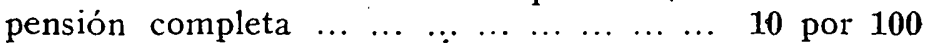

El gravamen girará sobre la cuenta, incluso el recargo del strvicio. Si no existiese carta o minuta especial y aun donde existan, se considerarán sujetas las consumiciones en cuanto que cxcluído el servicio y las partidas correspondientes a vinos, aperitivos, cafés, licores y demás propios de cafés, bares y establecimientos similares, sean superiores a 30 pesetas.

Con ello se establecería una uniformidad de tributación más justa y se evitarian las evasiones fiscales que se producen al amparo del cambio oficial de categoría, como nos ha ocurrido en Bilbao, llevándonos a un proceso de revisiones y reclamaciores aún en curso, en las que la Administración tiene que oponerse a clasificaciones del Sindicato Provincial de Hostelería y Similares.

Como dejamos dicho; el procedimiento de declaraciones ju- 
radas, complementado con un buen servicio de comprobación c inspección, parece debe ser el punto de partida de la experiencia municipal en la administración de este Impuesto.

Es, desde luego, un procedimiento laborioso y que requie$r e$ una buena organización, pero indudablemente si no se quiere operar un poco a ciegas al utilizar los procedimientos o de concuerto o de cobro a la entrada de las poblaciones, la Administración tiene que contar con datọ e información propia y directa cuando menos de un ejercicio.

En el procedimiento de concierto lo que se gana en comodidad y simplicidad, se pierde siempre en rendimientos y esto, que es una regla general para todas las exacciones, se tiene que acentuar mucho más, a mi juicio, en este Impuesto en el que aun con una buena organización del procedimiento de declaraciones juradas es difícil llegar al conocimiento real de las bases imponibles.

A este grave inconveniente se añade que como con arreglo a la regulación actual en materia de conciertos la duración mínima de los que se celebren ha de ser de dos años, es éste un lapso de tiempo lo suficientemente largo para que la Administración pierda la sensación y el conocimiento de la realidad y situación de los negocios de Hostelería y similares y del de Espectáculos, lo cual constituye un peligro grave, que le coloca en posición de inferioridad en sus relaciones con los contribuyentes, sobre todo para cuando tenga que tratar de la formalización de los nuevos o sucesivos conciertos, so pena de que interrumpa la aplicación de su empleo, para entrar por al. gún tiempo en la experiencia directa del procedimiento de las declaraciones juradas.

En una palabra, y empleando un simil deportivo, el procedimiento de conciertos implica una pérdida de entrenamiento con $t_{i}$ das sus consecuencias. No nos parece, por tanto, muy recomendable, porque además la organización y marcha del procedimiento de declaraciones juradas es barata comparada con el volumen de rendimientos $y$, por consiguiente, las economías que puedan obtenerse con el procedimiento de concierto son más hien teóricas y de escasísima importancia. En el Ayuntamiento 
de Bilbao el porcentaje medio de gastos de administración de este impuesto, con relación al rendimiento, viene a ser el de 0,70 por 100.

En cambio, y partiendo siempre de una primera experiencia del procedimiento de declaraciones juradas, es tentador a primera impresión el empleo del procedimiento de cobro a la entrada a las poblaciones.

En efecto, sin gran aúmento de gastos puesto que es utilizable el personal y los elementos de las líneas fiscales, fielatos y centros administrativos que tienen ya montados los Ayuntamientos para la aplicación de los Arbitrios sobre bebidas, alcoholes, carnes, caza y volatería, pescados y mariscos, y derechos de reconocimiento sanitario de artículos destinados al abasto de la población, puede organizarse el procedimiento para aplicarlo a los líquidos (vinos, cervezas, sidras, licores y bebidas), dejando el procedimiento de declaraciones juradas o de conciertos, para la otra parte de consumiciones, ventas y espectáculos.

Es decir, que el sistema habría de ser mixto.

Ahora bien, este procedimiento tiene el gran peligro de que hábiendo de ser altos los tipos de gravamen por unidad, se crea un estímulo considerable para el contrabando local, plaga contra la cual es muy difícil y dura la lucha en poblaciones de gran extensión y con líneas fiscales muy largas y complejas, en las que aun contando con una fidelidad y vigilancia extremadas del personal hay siempre medios de burlarlas y quebrantarlas.

Además, para emplear este procedimiento se precisa, por las razones expuestas en el apartado E), la unificación del tipo de gravamen de las bebidas y, aun conseguido esto, hay que tener mucho acierto al establecer los tipos de equivalencia de gravamen, ya que en ello se juega el éxito recaudatorio.

Las ventajas de este procedimiento en contraposición a sus graves peligros (contrabando y cálculo erróneo de los tipos de equivalencia de gravamen) consisten en su simplicidad, en que permite el aprovechamiento de medios fiscales ya organizados, y el refundir en una sola operación el control, aplicación y recaudación del Impuesto, del Arbitrio con fines no fiscales, del 
Impuesto sobre vinos y sidras corrientes de cinco pesetas hectolitro cedido a los Ayuntamientos y del Arbitrio municipal sobre bebidas espirituosas.

De todos modos, es el particular estudio y apreciación de los Fros y los contras del procedimiento y de los medios y caracterısticas del término y de sus contribuyentes el que dará a cada Ayuntamiento la pauta a seguir.

$\mathrm{Y}$ termino manifestando que todo lo expuesto no pasan de ser consideraciones generales que me ha sugerido la práctica del impuesto y que ahí quedan sin otras pretensiones que las de que puedan servir siquiera de información.

Andrés Arana Arrieta

Jefe de Hacienda del Excmo. Ayuntamiento de Bilbao. 